\title{
Pre-closure of Large-Sized Arterial Access Sites in Adults Undergoing Transcatheter Structural Interventions
}

Tahir Hamid • Tawfiq R. Choudhury • Bernard Clarke •

Vaikom S. Mahadevan

To view enhanced content go to www.cardiologytherapy-open.com

Received: November 19, 2014 / Published online: December 23, 2014

(c) The Author(s) 2014. This article is published with open access at Springerlink.com

\section{ABSTRACT}

Introduction: Patients undergoing structural heart interventions often require large-sized sheath insertion into femoral arteries and veins. Clinical outcome data on the use of suture-mediated devices for large femoral arterial access in structural heart interventions is limited. We assessed the efficacy of the Perclose $^{\mathrm{TM}}$ (Abbott Vascular Devices, Santa Clara, CA, USA) suture-mediated device using the pre-closure technique in achieving hemostasis in femoral arterial access sites following large sheath insertion ( $\geq 8 \mathrm{Fr}$ ).

Electronic supplementary material The online version of this article (doi:10.1007/s40119-014-0034-7) contains supplementary material, which is available to authorized users.

T. Hamid · T. R. Choudhury · B. Clarke .

V. S. Mahadevan ( $\square)$

Central Manchester University Hospitals,

Manchester Royal Infirmary, Oxford Road,

Manchester M13 9WL, UK

e-mail: vs.mahadevan@gmail.com

V. S. Mahadevan

University of California, San Francisco, L524, 505

Parnassus Avenue, San Francisco, CA 94143, USA
Methods: One hundred consecutive patients underwent 101 femoral artery access sites closures with the Perclose device using the pre-closure technique. Sixty-two percent of the patients were male and their mean (SD) age was $52( \pm 26)$ years. All patients received heparin.

Results: Mean arterial access site sheath diameter was $13 \pm 2 \mathrm{Fr}$. Immediate hemostasis was achieved in 96/101 (96\%) procedures ( $\leq 2 \mathrm{~min}$ ). Two patients ( $2 \%)$ had access siterelated complications requiring further interventions. On clinical follow up [mean (SD) follow-up of $24( \pm 12)$ months and median follow-up of 8.5 months], no complications were seen in the arterial access sites.

Conclusion: Pre-closure of large-size femoral arterial access sheath sites using the suturemediated Perclose device is efficacious in achieving rapid hemostasis in patients undergoing structural interventions. On 1-year follow-up, there were no arterial access site complications requiring further investigations or interventions.

Keywords: Hemostasis; Transcatheter aortic valve implantation (TAVI); Vascular closure device 


\section{INTRODUCTION}

Patients undergoing structural and congenital heart interventions usually require large-sized sheath insertion into the femoral arteries. This may increase the risk of developing access site vascular complications. Hence, active management of the femoral access site can potentially reduce the risk of vascular complications and allow early mobilization and discharge. The use of arterial closure devices is well established in patients undergoing diagnostic and percutaneous coronary interventions [1], percutaneous aortic balloon valvuloplasty (PABV) [2], and endovascular aortic procedures [3]. The use of the Perclose ${ }^{\mathrm{TM}}$ (Abbott Vascular Devices, Santa Clara, CA, USA) device in venous access sites has also been described [4-7]. Here, we describe the use of the Perclose suture-mediated device using the pre-closure technique in a series of 101 femoral arterial access site closures in patients undergoing congenital and structural heart interventions.

\section{METHODS}

Data from 100 consecutive patients who underwent large femoral arterial access $(\geq 8 \mathrm{Fr})$ site closures for congenital and structural interventions were analyzed retrospectively. Time to hemostasis, mobilization, and need for further intervention at the access site were analyzed. Patients had clinical follow-up reviews at 3 months and at 9-12 months. At follow-up, vascular assessment included checking for the femoral pulses, presence of hematoma, or signs of arterial occlusion. All the procedures were performed in a tertiary cardiac center, where there were vascular interventional and surgical services available. Patients with previous multiple vascular access, who had difficult arterial access due to extensive scarring, did not receive the Perclose device.

Major complications related to device were defined as the need for peri-procedural surgical or radiological intervention or bleeding requiring blood transfusion. The Perclose device efficacy was defined as achievement of hemostasis at the femoral arterial access site in $\leq 2 \mathrm{~min}$ following sheath removal and deployment of the predeployed sutures without the need for further manual compression.

\section{Pre-closure Technique}

Femoral arterial access was obtained by Seldinger technique [7]. After wire insertion, a 6 Fr dilator was used for dilatation. Subsequently, a $6 \mathrm{Fr}$ Perclose (A-T or Proglide; Abbott Vascular Devices) device was inserted and the wire was removed. Spontaneous blood flow through the side port was observed. The footplate of the device was deployed and the device pulled back and sutures set as usual. The footplates were released and the device partially retrieved until the port for the guide wire was visible (Figs. 1, 2). The guide wire was reintroduced into the artery and the device removed. An appropriately sized sheath was inserted. Upsizing of sheaths as

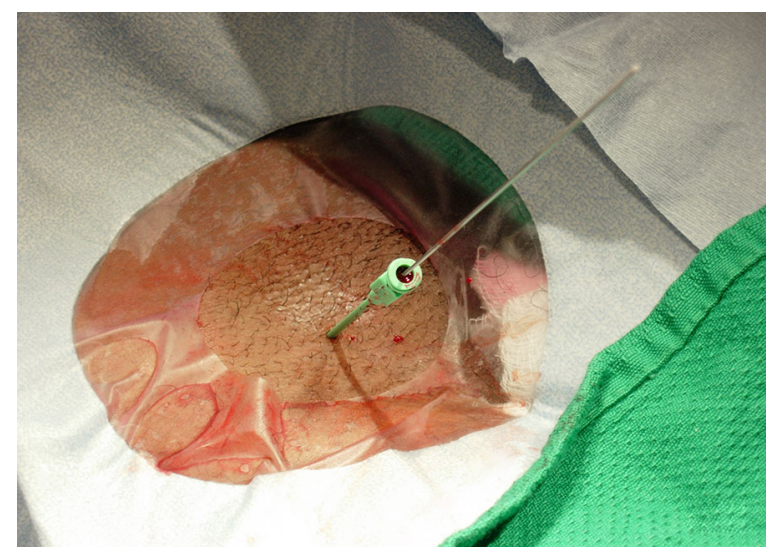

Fig. 1 Insertion of 6 Fr dilator over the wire following femoral vessel access 


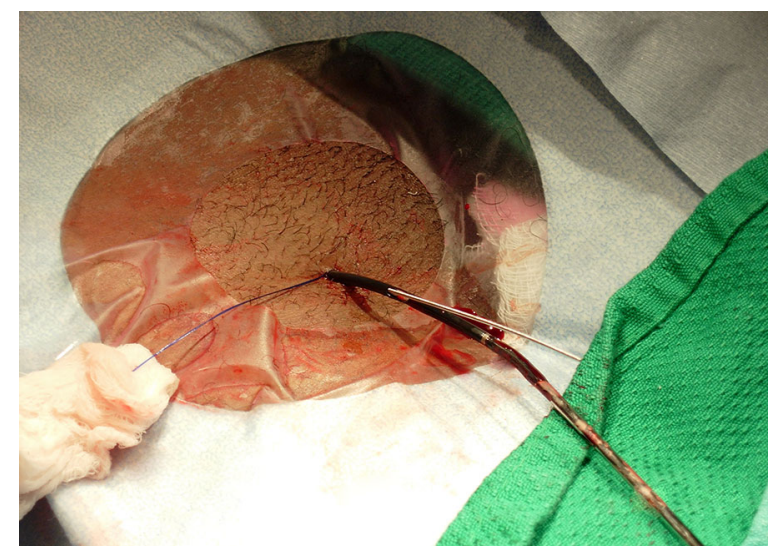

Fig. 2 Rewiring of the vessel following pre-deployment of the Perclose ${ }^{\mathrm{TM}}$ (Abbott Vascular Devices, Santa Clara, CA, USA) device

required was performed using normal techniques. The sutures were tightened at the end of the procedure upon removal of the sheath(s) from the vessel.

A single Perclose device was deployed for each arterial access up to $12 \mathrm{Fr}$ and two devices were pre-deployed at right angles to each other when sheath size was expected to be greater than 12 Fr. Fourteen patients who underwent transcatheter aortic valve implantation (TAVI) had two devices used per procedure.

\section{Compliance with Ethics Guidelines}

All procedures followed were in accordance with the ethical standards of the responsible committee on human experimentation (institutional and national) and with the Helsinki Declaration of 1975 , as revised in 2000 and 2008. Informed written consent for the procedure was obtained from all patients.

\section{RESULTS}

A total of 101 femoral arterial sites closures were performed in 100 consecutive patients over a period of 4 years. Of these, 14 underwent TAVI, 39 had PABV, and 47 underwent coarctation of the aorta (CoA) stenting. Sixty-two percent of the patients were male and their mean (SD) age was 52 ( \pm 26 ) years (range 16-95 years). Seventyseven $(77 \%)$ patients were hypertensive. All received anticoagulation with heparin during the procedure with a standard dose of 5,000 IU. The size of the sheaths used during the procedure ranged from 8 to $18 \mathrm{Fr}$ with a mean (SD) arterial sheath diameter of $13( \pm 2)$ Fr. Final sheath sizes were 12 Fr in 86 patients and 14 Fr in 14 patients.

\section{Post-procedural Outcomes}

Immediate hemostasis was achieved successfully in 96/101 (96\%) procedures. All patients were mobilized in $2 \mathrm{~h}$ except for patients requiring general anesthesia who were mobilized after $4 \mathrm{~h}$. Major complications in the form of pseudoaneurysm were seen in two patients (2\%). One required open vascular repair 2 weeks following the procedure, while the second was treated with thrombin injection. Five patients had mild access site oozing requiring manual compression for less than $30 \mathrm{~min}$ on the arterial access site. In five cases, the device failed to deploy on pre-closure initially, necessitating the use of a further device. There were two deaths in patients who underwent PABV. Both procedures were done as emergency procedures after presenting with cardiogenic shock in the setting of severe aortic stenosis. One patient died following TAVI after 7 days related to heart failure. None of the deaths were related to vascular access site complications and there was no significant drop in hemoglobin levels requiring a blood transfusion.

\section{Follow-up}

Ninety-six percent had clinical follow-up available with a mean (SD) follow-up of 24 $( \pm 12)$ months and median follow-up of 
8.5 months. There was no clinical evidence of access site infection or hematoma. There was no clinical evidence of limb ischemia and femoral pulses were palpable.

\section{DISCUSSION}

The Perclose device has been used for femoral arterial and venous closure in small-sized sheaths following percutaneous coronary intervention procedures $[1,3]$. The use of Perclose device leads to early hemostasis, early sheath removal, and early patient mobilization [6]. A meta-analysis of 30 studies by Nikolsky et al. [8] showed that Perclose and Angioseal ${ }^{\mathrm{TM}}$ (St. Jude Medical, St. Paul, MN, USA) were comparable to mechanical compression in obtaining arterial hemostasis in the setting of diagnostic coronary angiography and the risk of access site complications was similar. As all these studies were on coronary interventions, they generally used smaller arterial sheath sizes ( $\leq 6 \mathrm{Fr}$ ). Studies by Martin et al. [9] and Bangalore et al. [10] have shown lower deployment success and higher risk of vascular complications with Perclose compared with the Angioseal device. In our study, we had 39 patients, who underwent PABV, in whom we used 12 Fr sheaths with no vascular access site complications.

Forty-seven patients underwent successful Perclose device deployment to achieve complete homeostasis in patients who underwent stenting for CoA. To the best of our knowledge, no previous literature exists on pre-closure of the access site with the Perclose device for patients undergoing stenting for CoA. The American Heart Association currently recommends the use of femoral artery closure devices to achieve faster hemostasis, shorter duration of bed rest, and possibly improved patient comfort [11]. This study demonstrates that optimal results can be obtained with preclosure using a Perclose device for large-sized femoral arterial access in a wide range of congenital and structural heart interventions, including TAVI where large caliber arterial sheaths are required for valve implantation.

The use of the Perclose device in securing hemostasis in the venous access sites has also been described more recently. Shaw et al. [4] and Mahadevan et al. [6] have reported the use of Perclose for femoral venous closure and maintenance of venous patency as assessed by Doppler following such closure. A recent study by Hamid et al. [7] described the successful use of the device in 310 large femoral venous access sites $(\geq 8 \mathrm{Fr}$ ) in 243 patients undergoing structural heart interventions. Mylonas et al. [5] reported use of Perclose closure device for access site management after using $14 \mathrm{Fr}$ femoral venous sheaths for antegrade PABV.

This study demonstrates that Perclose device can be used safely and effectively for large-sized femoral arterial access in a wide range of congenital and structural heart interventions. Similarly, we used Perclose devices in TAVI where large caliber arterial sheaths are required for valve implantation.

\section{Limitations}

This is a retrospective series with no control group that underwent manual compression or other form of repair to compare efficacy in a more objective manner. There may also be the possibility of operator bias in choosing cases for pre-closure.

\section{CONCLUSION}

Pre-closure with the Perclose suture technique for femoral arterial sites following the insertion of large-sized sheaths (8 Fr or above) for cardiac 
interventions is safe and effective, with a low risk of vascular access site complications. Clinical follow-up showed no significant complications in the arterial access sites.

\section{ACKNOWLEDGMENTS}

No funding or sponsorship was received for this study or publication of this article. All named authors meet the ICMJE criteria for authorship for this manuscript, take responsibility for the integrity of the work as a whole, and have given final approval for the version to be published.

Conflict of interest. Tahir Hamid, Tawfiq R. Choudhury, Bernard Clarke, and Vaikom S. Mahadevan declare no conflicts of interest.

Compliance with ethics guidelines. All procedures followed were in accordance with the ethical standards of the responsible committee on human experimentation (institutional and national) and with the Helsinki Declaration of 1975 , as revised in 2000 and 2008. Informed written consent for the procedure was obtained from all patients.

Open Access. This article is distributed under the terms of the Creative Commons Attribution Noncommercial License which permits any noncommercial use, distribution, and reproduction in any medium, provided the original author(s) and the source are credited.

\section{REFERENCES}

1. Lee SW, Ho HH, Kong SL, et al. Long term clinical outcomes after deployment of femoral vascular closure devices in coronary angiography and percutaneous coronary intervention. Catheter Cardiovasc Interv. 2010;75:345-8.

2. Michaels $\mathrm{AD}$, Ports TA. Use of a percutaneous arterial suture device (Perclose) in patients undergoing percutaneous balloon aortic valvuloplast. Catheter Cardiovasc Interv. 2001;53:445-7.

3. Lee WA, Brown MP, Nelson PR, Huber TS, Seeger JM. Midterm outcomes of femoral arteries after percutaneous endovascular aortic repair using the Preclose technique. J Vasc Surg. 2008;47:919-23.

4. Shaw JA, Dewire E, Nugent A, Eisenhauer AC. Use of suture-mediated vascular closure devices for the management of femoral vein access after transcatheter procedures. Catheter Cardiovasc Interv. 2004;63:439-43.

5. Mylonas I, Sakata Y, Salinger M, Sanborn TA, Feldman T. The use of percutaneous suturemediated closure for the management of 14 French femoral venous access. J Invasive Cardiol. 2006;18:299-302.

6. Mahadevan VS, Jimeno S, Benson LN, McLaughlin PR, Horlick EM. Pre-closure of femoral venous access sites used for large-sized sheath insertion with the Perclose device in adults undergoing cardiac intervention. Heart. 2008;94:571-2.

7. Hamid T, Rajagopal R, Pius C, Clarke B, Mahadevan $\mathrm{V}$. Pre-closure of large-sized femoral venous access sites in adults undergoing trans-catheter structural interventions. Catheter Cardiovasc Interv. 2013;81:586-90.

8. Nikolsky E, Mehran R, Halkin A, et al. Vascular complications associated with arteriotomy closure devices in patients undergoing percutaneous coronary procedures: a meta-analysis. J Am Coll Cardiol. 2004;44:1200-9.

9. Martin JL, Pratsos A, Magargee E, et al. A randomized trial comparing compression, Perclose Proglide and Angio-Seal VIP for arterial closure following percutaneous coronary intervention: the CAP trial. Catheter Cardiovasc Interv. 2008;71:1-5.

10. Bangalore S, Arora N, Resnic FS. Vascular closure device failure: frequency and implications: a propensity-matched analysis. Circ Cardiovasc Interv. 2009;2:549-56.

11. Patel MR, Jneid H, Derdeyn CP, et al. Arteriotomy closure devices for cardiovascular procedures: a scientific statement from the American Heart Association. Circulation. 2010;122:1882-93. 